\title{
Management of Type 2 Diabetes in Developing Countries: Balancing Optimal Glycaemic Control and Outcomes with Affordability and Accessibility to Treatment
}

\author{
Viswanathan Mohan · Kamlesh Khunti - Siew P. Chan · Fadlo F. Filho · Nam Q. Tran · \\ Kaushik Ramaiya · Shashank Joshi · Ambrish Mithal • Maïmouna N. Mbaye $\cdot$ Nemencio A. Nicodemus Jr. \\ Tint S. Latt $\cdot$ Linong Ji $\cdot$ Ibrahim N. Elebrashy $\cdot$ Jean C. Mbanya
}

Received: October 2, 2019 / Published online: November 26, 2019

(C) The Author(s) 2019

\begin{abstract}
With the growing prevalence of type 2 diabetes, particularly in emerging countries, its management in the context of available resources should be considered. International guidelines, while comprehensive and scientifically valid, may not be appropriate for regions such as Asia, Latin America or Africa, where epidemiology, patient phenotypes, cultural conditions and socioeconomic status are different from America and Europe. Although glycaemic control and reduction of micro- and
\end{abstract}

Enhanced Digital Features To view enhanced digital features for this article go to https://doi.org/10.6084/ m9.figshare.10284044.

V. Mohan $(\bowtie)$

Dr. Mohan's Diabetes Specialities Centre and

Madras Diabetes Research Foundation, Chennai,

Tamil Nadu, India

e-mail: drmohans@diabetes.ind.in

K. Khunti

Diabetes Research Centre, University of Leicester, Leicester, UK

S. P. Chan

Department of Medicine, Faculty of Medicine,

University of Malaya, Kuala Lumpur, Malaysia

F. F. Filho

Faculty of Medicine, ABC Foundation, Santo André, Brazil

N. Q. Tran

Department of Endocrinology, University Medical

Center, Ho Chi Minh City, Vietnam macrovascular outcomes remain essential aspects of treatment, access and cost are major limiting factors; therefore, a pragmatic approach is required in restricted-resource settings. Newer agents, such as sodium-glucose cotransporter 2 inhibitors and glucagon-like peptide 1 receptor agonists in particular, are relatively expensive, with limited availability despite potentially being valuable for patients with insulin resistance and cardiovascular complications. This review makes a case for the role of more accessible second-line treatments with long-established efficacy and affordability, such as sulfonylureas, in the management of type 2 diabetes, particularly in developing or restricted-resource countries.

\author{
K. Ramaiya \\ Shree Hindu Mandal Hospital, Dar es Salaam, \\ Tanzania \\ K. Ramaiya \\ Department of Internal Medicine, Muhimbili \\ University of Health and Allied Sciences, Dar es \\ Salaam, Tanzania \\ S. Joshi \\ Lilavati Hospital and Research Centre, Mumbai, \\ Maharashtra, India \\ A. Mithal \\ Medanta-The Medicity, Gurugram, Haryana, India \\ M. N. Mbaye \\ Cheikh Anta Diop University, Dakar, Senegal
}


Keywords: Cost-effectiveness; control; Sulphonylureas; Type 2 diabetes

\section{Key Summary Points}

\section{Why carry out this study?}

Diabetes mellitus is becoming a global epidemic but it disproportionally affects poorer developing countries. Newer agents, although increasingly recognized by some international guidelines, are not always widely accessible and affordable, unlike long-standing drugs such as sulfonylureas (SUs)

This review considers existing antidiabetic drugs and makes a case for appropriateness of SUs, especially newer generation SUs

\section{What was learned from the study?}

The newer drugs like DPP4 inhibitors, SGLT2 inhibitors and GLP-1 receptor agonists, while showing benefits, may not be affordable and accessible for many individuals in developing countries

The newer generation SUs like gliclazide and glimepiride are time-tested, effective, safe and should continue to be used especially in resource-restricted settings
N. A. Nicodemus Jr.

Department of Medicine, University of the

Philippines-Philippine General Hospital, Manila, Philippines

\section{N. A. Nicodemus Jr.}

Department of Biochemistry and Molecular Biology,

University of the Philippines-College of Medicine,

Manila, Philippines

T. S. Latt

Department of Diabetes and Endocrinology,

University of Medicine 2, Yangon, Myanmar

L. Ji

Department of Endocrinology, Peking University

People's Hospital, Beijing, China

\section{INTRODUCTION}

It is estimated that in 2015 alone, diabetes mellitus directly caused 1.6 million deaths [1], while in 2017, an estimated 4 million deaths were attributed to diabetes and its complications [2]. Worldwide, over 425 million people are estimated to be living with diabetes, and this number is expected to increase significantly to 629 million by 2045 (Fig. 1) [2].

Once considered a disease of affluent countries, nearly $80 \%$ of people with diabetes, mainly type 2 , now live in low- and middle-income countries [2]. Furthermore, its prevalence is rapidly rising, with the largest increases foreseen in Africa, the Middle East, South East Asia and Central America [2]. Worldwide, the increase in the proportion of people over 65 years old is a major factor driving the increased prevalence of diabetes [3], but in lowand middle-income settings, there are other factors involved including increase in certain unhealthy lifestyle factors, such as diet and sedentary lifestyles [4]; genetic susceptibility $[5,6]$, particularly in those settings where patients are exposed to obesogenic environments characterized by sedentary behaviour and excessive sugar and fat consumption [7]; and unique patient phenotypes, such as higher glycated haemoglobin (HbA1c) levels, an earlier, often more aggressive, onset of disease and also initial presentation at lower degrees of obesity, particularly in South Asia and India [8-12].

\author{
I. N. Elebrashy \\ Department of Internal Medicine, Diabetes, and \\ Endocrinology, Faculty of Medicine, Cairo \\ University, Giza, Egypt \\ J. C. Mbanya \\ University of Yaoundé I, Yaoundé, Cameroon \\ J. C. Mbanya \\ National Obesity Center, Central Hospital of \\ Yaoundé, Yaoundé, Cameroon
}




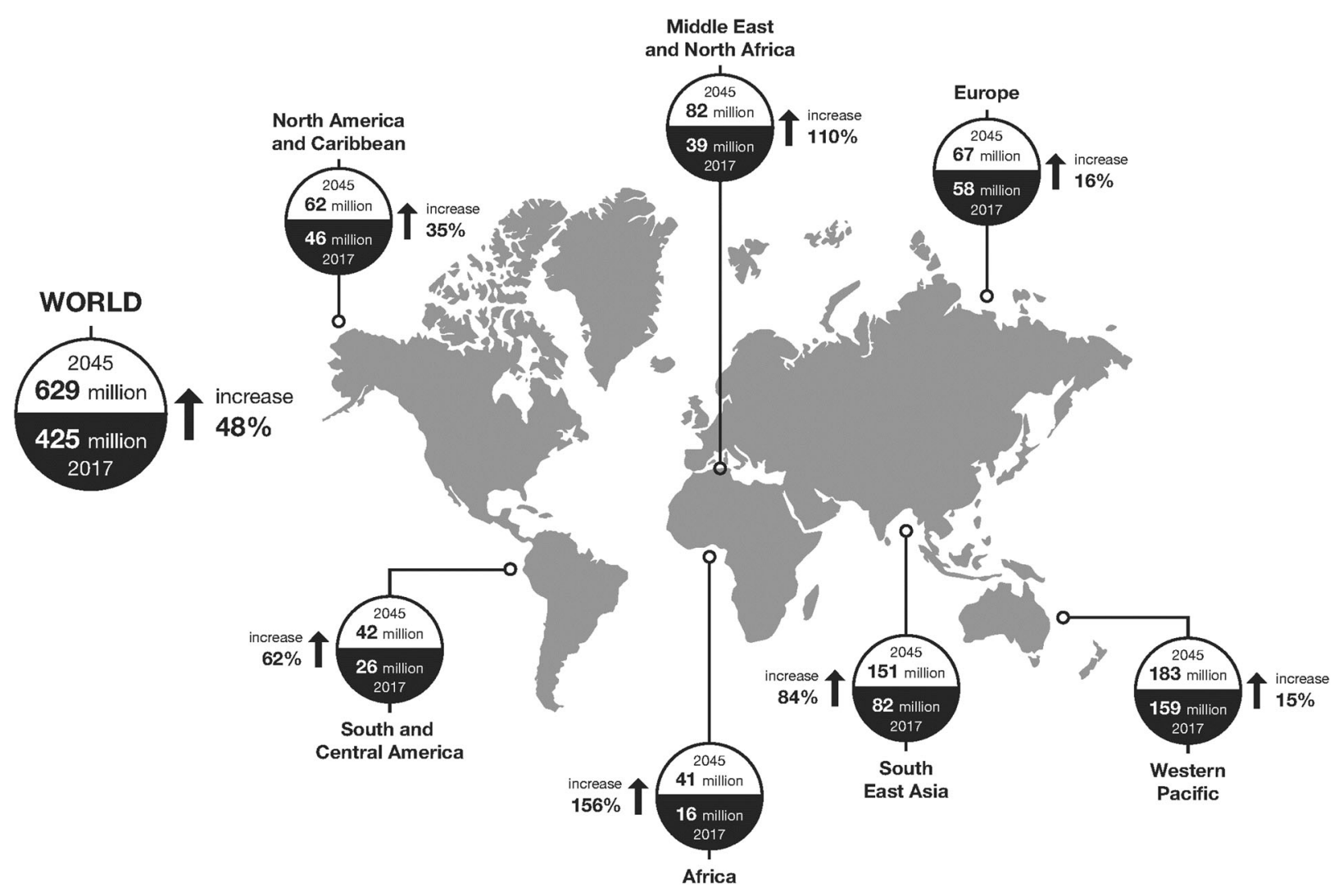

Fig. 1 Number of people with diabetes worldwide and per region in 2017 and 2045 (aged 20-79 years) [2]. Adapted with permission from the International Diabetes Federation ('Access to Medicines and Supplies for People with

Management of type 2 diabetes in these settings is suboptimal, often because of challenges with access to medications (globally, patients typically pay 'out of pocket') [13-15]. Additionally, increased co-morbid disorders associated with diabetes and a growing population of patients for whom resources must be distributed mean that medications are severely limited $[14,16]$. A major barrier to optimal care is the delivery system, which is often fragmented, lacks clinical information and capabilities, and is poorly designed for the coordinated delivery of chronic care. Implementation of optimal diabetes management requires an organized systematic approach and the involvement of a coordinated and dedicated team, which can often be lacking in clinical practice [17]. Importantly, there are also often delays in
Diabetes'. 2016. http://www.idf.org/accesstomedicine; IDF Diabetes Atlas, 8th edn. 2017. http://www. diabetesatlas.org)

diagnosis, creating a greater burden of disease after onset of complications [18].

The shortage of resource-specific management guidelines may play a contributory role in poor disease management, as identified in a recent systematic review that highlighted the impact of poor or inappropriate guidance for care providers, patients, policymakers and payers in resource-restricted settings, ultimately leading to suboptimal patient outcomes [19]. Additionally, the phenotype of populations targeted by US and European guidelines may not be directly applicable to patients in poorer regions of the world [14]. The recent World Health Organization (WHO) guidelines are among the first to have taken into account low resources and regional specificities, bearing in mind that the majority of patients with type 2 
diabetes mellitus are from low- to middle-income countries [1].

Control of glycaemia remains the cornerstone of management of people with type 2 diabetes. The recent consensus report by the American Diabetes Association (ADA) and European Association for the Study of Diabetes (EASD) and the ADA Standards of Medical Care in Diabetes provided updated recommendations on the management of hyperglycaemia in type 2 diabetes, including the choice of glucoselowering medication [20, 21]. In addition to long-standing and effective glucose-lowering therapies, such as metformin and second-line sulfonylureas, new and effective glucose-lowering agents, including sodium-glucose cotransporter 2 inhibitors (SGLT2i), dipeptidyl peptidase 4 inhibitors (DPP4i) and glucagonlike peptide 1 receptor agonists (GLP-1RA), have also been shown to provide benefits [22]. However, their use may be limited by affordability, accessibility, side effects and patient preferences in terms of route of administration [20]. Therefore, a more pragmatic approach to the management of diabetes may be required, particularly when resources are limited.

Consistent with the ADA/EASD consensus statement, a patient-centred approach is the key [20]. Factors such as efficacy in achieving glycaemic control, reduction of microvascular and macrovascular outcomes, safety, patient adherence and barriers, such as cost and access to therapies, must be considered when deciding on a treatment for type 2 diabetes. Considering all of these factors, and particularly where cost is an issue, the ADA/EASD consensus statement recommends metformin followed by a secondline sulfonylurea [20].

This review will, therefore, consider the evidence for efficacy, outcomes, availability and accessibility of these treatment options in the management of type 2 diabetes in restricted-resource settings.

\section{Compliance with Ethics Guidelines}

This article is based on previously conducted studies and does not contain any studies with human participants or animals performed by any of the authors.

\section{SEARCH STRATEGY AND SELECTION CRITERIA}

References for this review were identified through searches of PubMed for articles published from January, 2015 to November, 2018 by use of the terms "Cost", "Cost effectiveness", "Health economics", "Low income", "Middle income", "Maturing country", "Low resource", "Glycaemic control", "Access", "Affordability", "Treatment initiation" and "Treatment persistence", with therapies comprising "Sulfonylurea", "DPP4i", "SGLT2i" and "GLP-1RA". Articles resulting from these searches and relevant references cited in those articles were reviewed.

\section{GLYCAEMIC CONTROL REMAINS FUNDAMENTAL IN TYPE 2 DIABETES MANAGEMENT}

Achieving and maintaining tight glycaemic control is an essential principle in managing diabetes to avoid related complications [23, 24]. Specifically, early intensive glycaemic control (to achieve an HbA1c value of $7.0 \%$ or less) reduces renal complications when compared to standard regimens and has been shown to be safe in terms of cardiovascular outcomes, highlighting its role in the prevention of microvascular complications [25].

Unfortunately, in type 2 diabetes, specifically in the developing world, the opportunity for early intensive intervention is often limited: patients are diagnosed late with increased levels of $\mathrm{HbA} 1 \mathrm{c}$, and morbidity and diabetes-related mortality are high $[19,26]$. Indeed, type 2 diabetes is frequently only recognized when lifethreatening complications develop [13]. With its increasing prevalence, access to the most effective, well-tolerated therapies that lower blood glucose levels in type 2 diabetes is more important than ever [27, 28].

As a result of its high efficacy in lowering HbA1c, its favourable safety profile, low cost 
and widespread availability, metformin remains the first-line medication for management of type 2 diabetes [20,21, 29, 30]. Several options exist when metformin is not well tolerated or becomes inadequate alone in achieving glucose targets, including sulfonylureas and insulin, as well as the newer glucose-lowering therapies SGLT2i, DPP4i and GLP-1RA.

While these novel treatments may offer some advantages over older glucose-lowering agents, especially in patients with established cardiovascular disease (SGLT2i, GLP-1RA), they do come with restrictions, as they are typically costly or less effective (DPP4i, SGLT2i) and have their own share of side effects, such as gastrointestinal disturbances, pancreatitis and infections (SGLT2i) [31].

With this in mind, considering treatment options for patients in restricted-resource settings, this part of the review will focus specifically on evidence for second-generation sulfonylureas, such as gliclazide and glimepiride, as well as newer agents, such as SGLT2i, DPP4i and GLP-1RA.

\section{Reducing HbA1c}

Several landmark trials have established the association of sulfonylureas with an effective reduction in HbA1c and improved long-term outcomes [23, 25, 32-34]. Importantly, sulfonylureas and metformin provided the best HbA1c goal achievement (less than 7\%) in a systematic review of 218 randomized controlled trials comprising 79,000 patients, with rates of $48 \%$ and $42 \%$, respectively [35]. In another systematic review and meta-analysis of sulfonylurea efficacy, sulfonylurea monotherapy lowered $\mathrm{HbA} 1 \mathrm{c}$ by $1.51 \%(17 \mathrm{mmol} / \mathrm{mol})$ when compared to placebo [95\% confidence interval (CI) $1.25,1.78]$. When added to other oral glucose-lowering therapies, in particular metformin, sulfonylureas lowered HbA1c by $1.62 \%$ (18 mmol $/ \mathrm{mol} ; 95 \%$ CI 1.0, 2.24); sulfonylureas with insulin lowered $\mathrm{HbA1c}$ by $0.46 \%$ ( $6 \mathrm{mmol} / \mathrm{mol}$; 95\% CI 0.24, 0.69) and enabled the insulin dose to be reduced [36].

Unfortunately, despite well-established benefits in glycaemic efficacy (Fig. 2), reduced costs

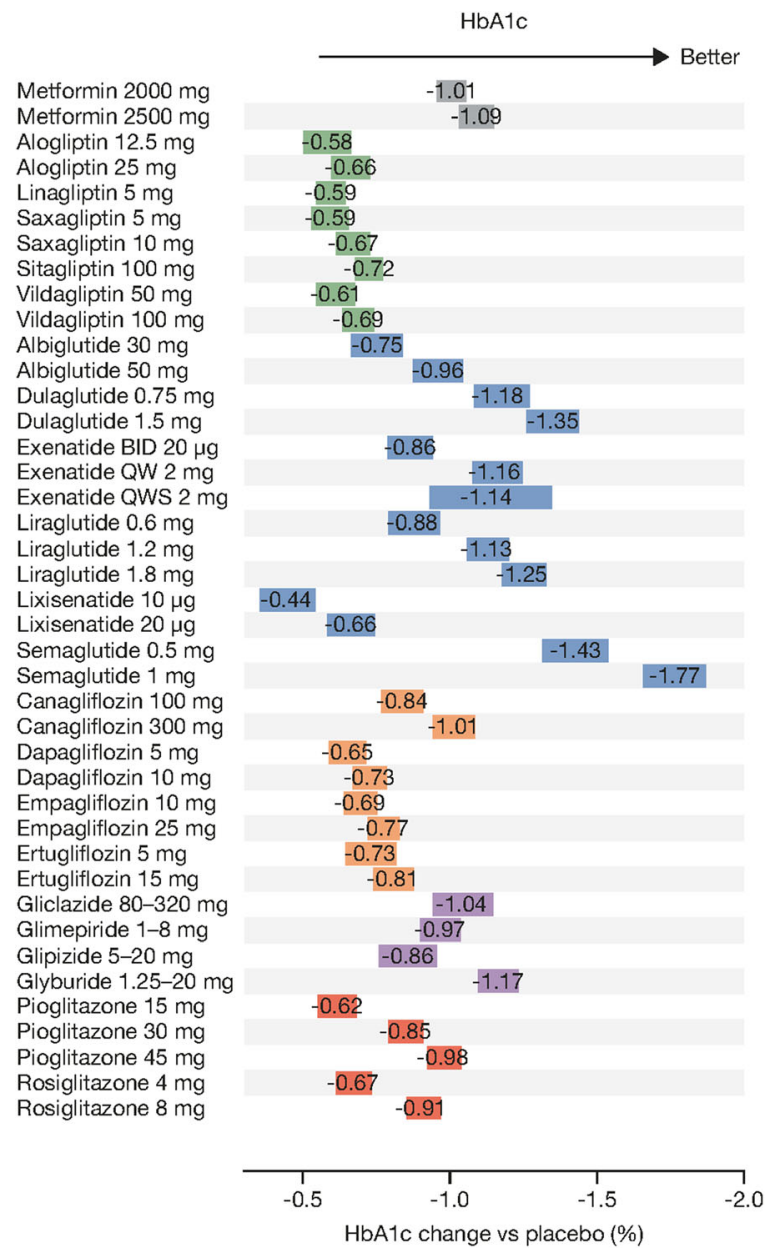

Fig. 2 HbAlc reduction by molecule and dosage (drugnaive population with a baseline $\mathrm{HbAlc}$ of $8.0 \%$ and a baseline weight of $90 \mathrm{~kg}$, after 26 weeks of treatment) [37]. Boxes represent standard deviation. BID twice a day, HbAlc glycated haemoglobin, QW once a week, QWS auto-injection. Reproduced with permission from Maloney et al. [37]

and reduced side effects associated with the second-generation sulfonylureas, when compared with other glucose-lowering therapies, they remain underutilized, even in low-resource settings [32, 37]. Reluctance to use sulfonylureas may stem from trials showing increased risk of hypoglycaemia and questioning cardiovascular safety [38]. Further information on cardiovascular safety data and the risk of hypoglycaemia associated with sulfonylureas can be found later in this review. 


\section{Durability}

While sulfonylureas can rapidly achieve significant improvements in glycaemic control without necessitating add-on therapy for an extended period, there is some evidence that durability of response may differ from that of other oral drugs.

The TOSCA.IT and RECORD trials compared sulfonylureas and thiazolidinediones added to metformin as dual therapy over a follow-up period of approximately 5 years and reported that the rate of increase of HbA1c was only slightly, albeit significantly, greater with sulfonylureas compared with a thiazolidinedione $[39,40]$.

A meta-analysis including 66 randomized controlled trials with a duration of at least 12 weeks compared SGLT2i with non-SGLT2i agents in type 2 diabetes. Results showed that compared to DPP4i, SGLT2i had a better persistence of efficacy, at least up to 2 years. Sulfonylureas were more effective in the short term but less effective in the longer term when compared to SGLT2i [41].

A meta-analysis of eight randomized controlled trials with a duration of at least 104 weeks suggested that long-term treatment with DPP4i conferred better durability of glycaemic response than sulfonylureas in patients with type 2 diabetes [42]. Contrasting with these results, a retrospective cohort study of 20,070 patients showed that, in routine clinical practice, DPP4i were associated with an increased, earlier requirement for treatment intensification compared to sulfonylureas or thiazolidinediones [43]: the mean time to treatment failure among thiazolidinedione users was the longest (3.3 years), followed by sulfonylurea users (2.4 years) and then DPP4i users (1.6 years). A meta-analysis of 12 longterm randomized controlled trials of DPP4i with durations of 108 weeks or less found that their effect on HbA1c declined during the second year of treatment [44].

A recent retrospective study was conducted in 325 patients with type 2 diabetes aged at least 90 years selected from a large tertiary diabetes centre (more than 470,000 patients). Interestingly, the majority of these patients with very long disease duration (mean \pm standard deviation, $23 \pm 14$ years) were on sulfonylureas as monotherapy (64.9\%), mainly gliclazide and glimepiride, compared to $43.9 \%$ in matched 50-60-year-old patients with type 2 diabetes [45]. As long-term survivors with type 2 diabetes were reported to have a better control of glycaemia [46], these findings suggest that sulfonylureas could be effective and safe over a long period.

Nevertheless, in many cases, diabetes will ultimately require intensification of treatment with time, and further evidence is required to definitively evaluate the clinical impact of interclass differences in durability. The ongoing GRADE (Glycemia Reduction Approaches in Diabetes: a comparative Effectiveness study) trial will compare glycaemic control with four drug classes (sulfonylureas, DPP4i, GLP-1RA and basal insulin) when added to metformin therapy over 4 years in patients with recent-onset type 2 diabetes [47].

\section{Managing Macro- and Microvascular Complications in Type 2 Diabetes}

Reducing both major macrovascular events (such as death from cardiovascular causes, nonfatal myocardial infarction or non-fatal stroke) and microvascular events (such as new or worsening nephropathy or retinopathy) is essential in improving patient outcomes in type 2 diabetes, especially early in the disease [20].

\section{Macrovascular Complications}

Concerns regarding sulfonylureas and cardiovascular complications have been addressed by a number of studies showing no difference in the risk of major adverse cardiovascular events or all-cause mortality between second-generation sulfonylureas and other classes of oral glucose-lowering agents [14, 38, 48, 49]. The ADVANCE trial found that, compared to standard control, intensification of gliclazide modified release (MR) treatment was associated with long-term benefits on microvascular end points (new or worsening nephropathy and new or worsening retinopathy) in addition to effective 


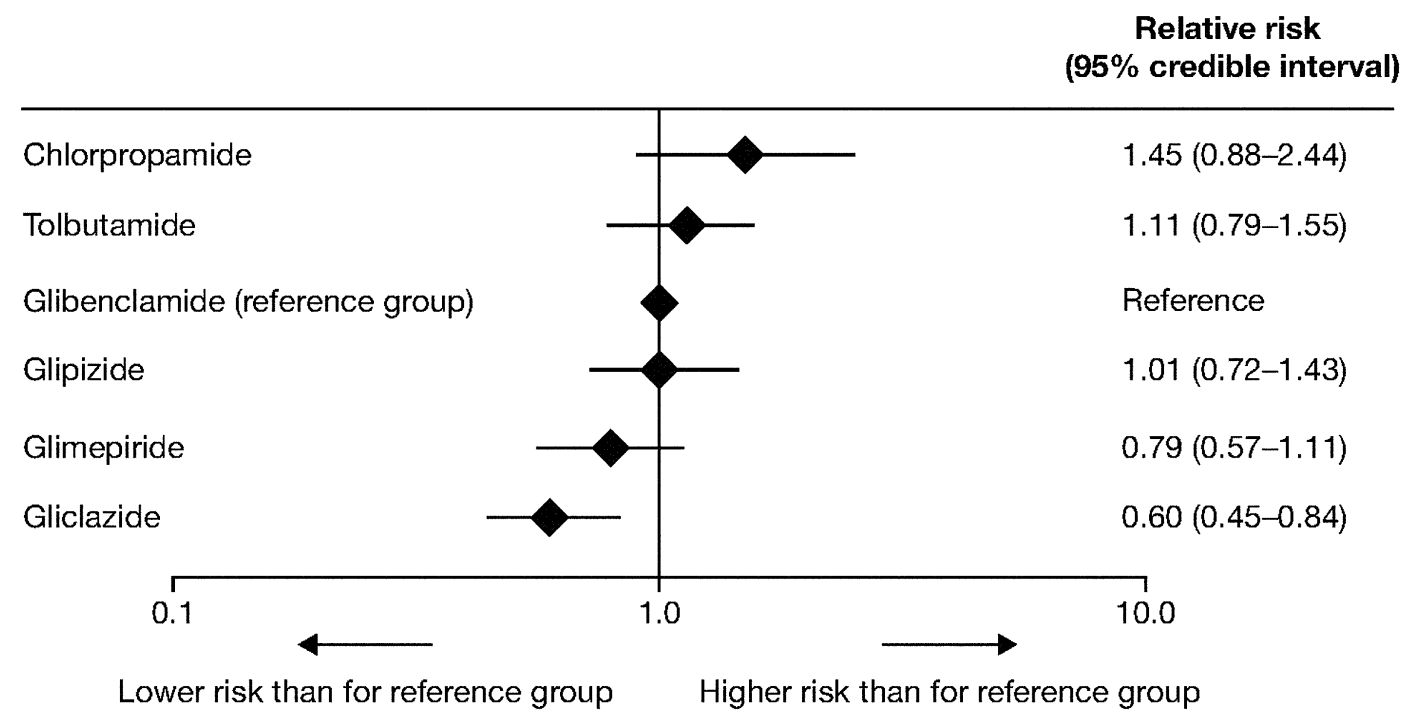

Fig. 3 Cardiovascular-related mortality risk associated with sulfonylureas [38]. Reproduced with permission from Simpson et al. [38]

glycaemic control [25]. Additionally, as mentioned earlier, a network meta-analysis of direct and indirect evidence from 13 studies showed that later-generation sulfonylureas such as gliclazide and glimepiride are associated with a lower risk of all-cause cardiovascular-related mortality, whereas other sulfonylureas failed to show significant benefit (Fig. 3) [38]. The TOSCA.IT primary prevention trial has also provided reassuring evidence for the cardiovascular safety of second-generation sulfonylureas ( $n=1493 ; 2 \%$ glibenclamide $[n=24], 48 \%$ glimepiride $[n=723], 50 \%$ gliclazide $[n=745])$. This investigator-initiated trial showed similar cardiovascular event incidence for sulfonylurea treatment compared with pioglitazone as addon to metformin [40].

With regards to newer agents, multiple cardiovascular outcomes trials (CVOTs), including the EMPA-REG, CANVAS, LEADER, SUSTAIN-6 and ELIXA trials, have provided significant evidence to support the extended benefit of GLP1RA and SGLT2i in managing type 2 diabetes, above all, cardiovascular benefits [20]. However, results have been heterogeneous within drug classes. Table 1 shows an overview of the effect of different drug classes on multiple outcomes, including cardiovascular outcomes [21, 50]. Notably, treatment with SGLT2i shows lower rates of death and heart failure regardless of the presence of established cardiovascular disease, suggesting that the benefit from SGLT2i extends across the continuum of cardiovascular risk $[51,52]$. It is important to note that in the vast majority of CVOTs, patients are typically on metformin and a large proportion also use sulfonylureas $[53,54]$. The cardiovascular benefit is thus obtained 'on top of' these essential treatments. In addition, in this era of new CVOTs, it is important to note that until the release of the new CAROLINA data, there was a significant lack of trials directly comparing these agents to sulfonylureas, and comparisons of cardiovascular safety could not objectively be made [55]. The head-to-head study CAROLINA was the first CVOT to compare the sulfonylurea glimepiride to the DPP4i linagliptin over a 6-year period in more than 6000 adults with type 2 diabetes, and found no difference in cardiovascular risk between groups $[55,56]$. Consistent with other studies, the CAROLINA trial found increased cases of hypoglycaemia in the glimepiride-treated group compared with the linagliptin group. The mechanism behind this finding and practical advice on how to manage hypoglycaemia are considered later in this paper. Importantly, the CAROLINA trial provided reassuring cardiovascular safety data regarding sulfonylureas 


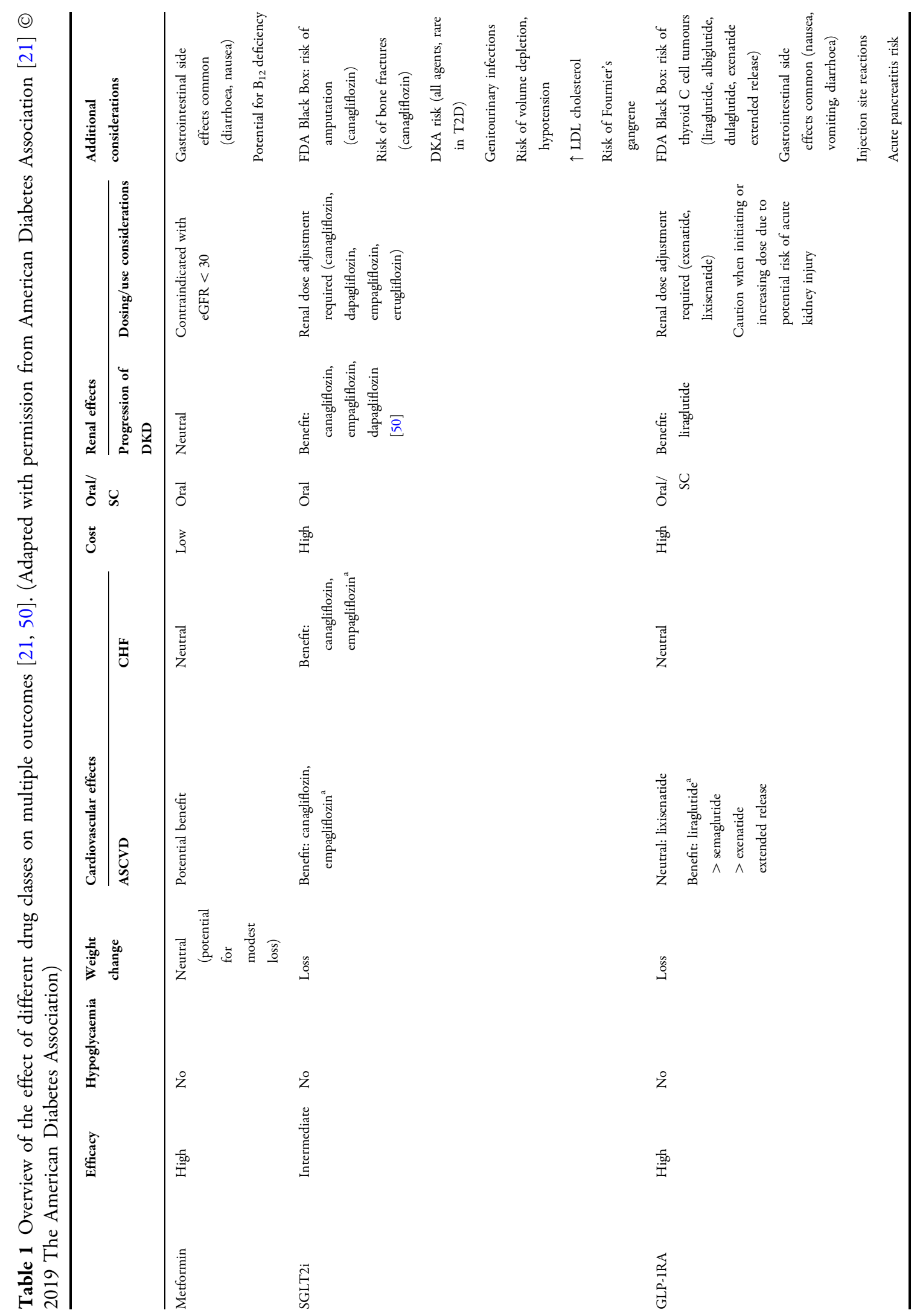




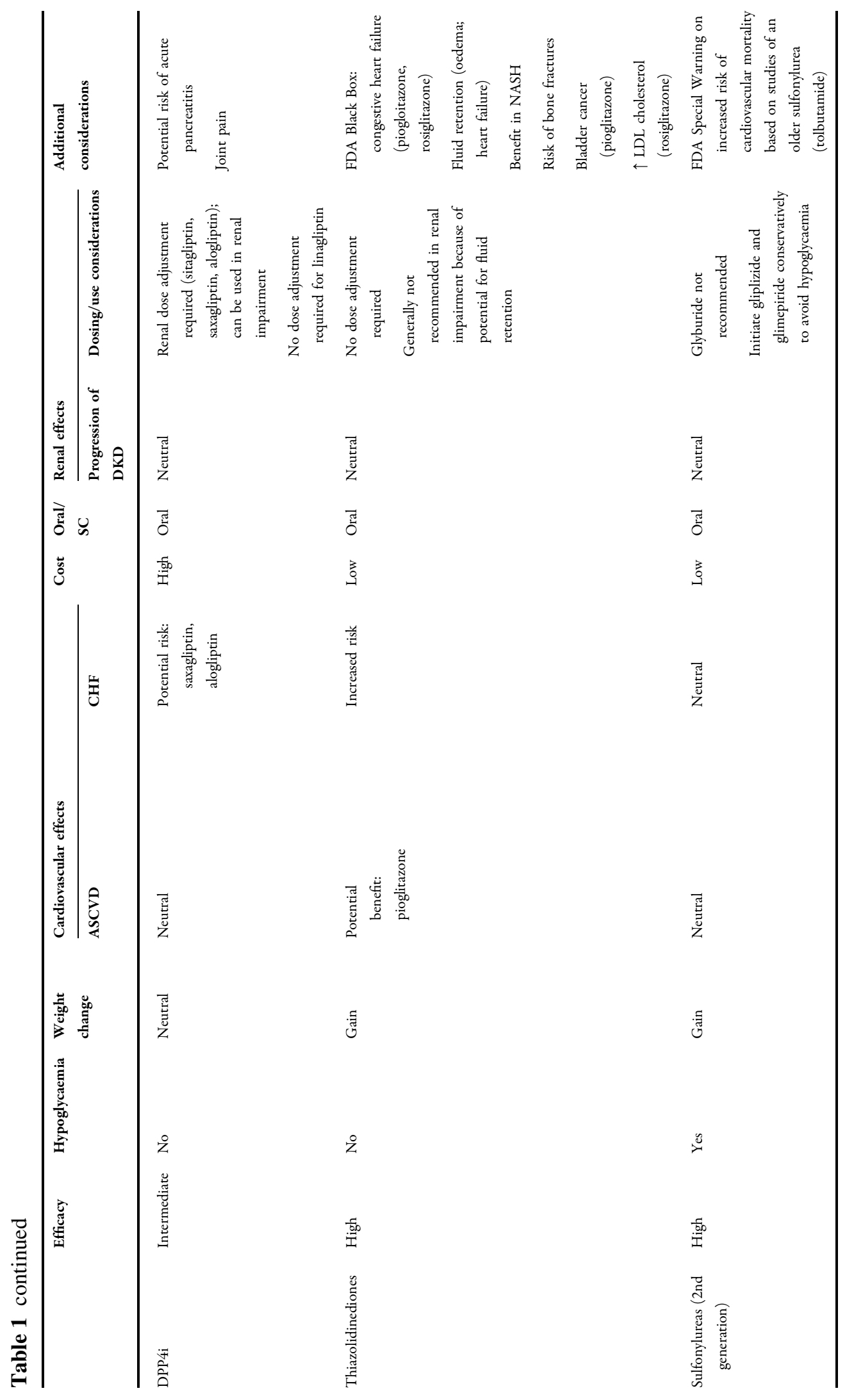




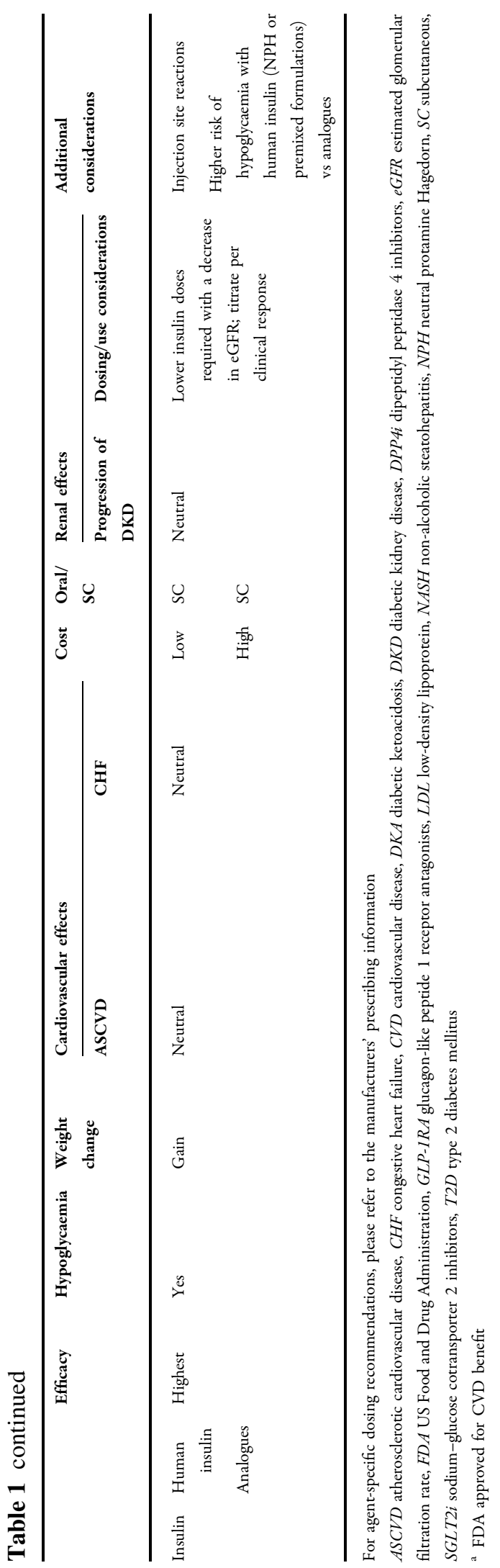

and supports their continued use as long as they are less costly than newer agents [55].

\section{Microvascular Complications}

Effective and safe treatment options for type 2 diabetes that also demonstrate benefits in renal outcomes are essential: up to $50 \%$ of patients with type 2 diabetes will suffer diabetic kidney disease at some point in their lives [2]. Therefore, improving the prognosis of at-risk patients is critical. While some of the new CVOTs have not studied the reduction of these events [54], others involving SGLT2i and GLP-1RA in particular have shown potential renal benefits $[53,57]$. Most notably, the recent CREDENCE trial found that the SGLT2i canagliflozin reduced the relative risk of end-stage kidney disease by 30\% when compared to placebo [58]. However, apart from high cost and low accessibility, limitations to the uptake of these therapies include intolerance to injectable therapies (insulin, GLP-1RA) and need for close monitoring of kidney function for SGLT2i [59].

The benefit of sulfonylureas on microvascular outcomes was initially demonstrated in the UK Prospective Diabetes Study (UKPDS) trial that compared the effects of intensive versus conventional glucose control. The trial found that intensive treatment with sulfonylureas decreased the risk of microvascular complications in type 2 diabetes mellitus by 25\% [23]. Long-term follow-up studies of sulfonylureas demonstrated that an initial phase of intensive glycaemic control protects against long-term development of end-stage renal disease in type 2 diabetes. Intensive glucose lowering based on gliclazide MR in the ADVANCE study showed significant benefits from reduction of new-onset microalbuminuria, regression to normoalbuminuria and reduction of progression to end-stage renal disease $[25,60]$.

Real-world evidence from ongoing trials will potentially help to validate if patients in CVOTs reflect real-life clinical practice. But current evidence shows that second-generation sulfonylureas are a cost-effective option for type 2 diabetes to reduce disease burden, providing efficient glycaemic control, cardiovascular safety and renal benefits [2, 20, 25]. In addition, while the new CVOT data and the expanding 
treatment landscape are positive steps forwards in managing type 2 diabetes, when considering the associated need for greater knowledge, it is evident why the use of sulfonylureas, with their tried, tested and well-known profile, may be preferred [55].

\section{HYPOGLYCAEMIA, WEIGHT GAIN AND OTHER MAJOR ADVERSE EVENTS}

In the management of type 2 diabetes, treating physicians must consider the risks versus benefits of the chosen therapy. Generally, adverse events associated with treatment of type 2 diabetes (including SGLT2i, DPP4i, GLP-1RA, metformin, insulin and sulfonylureas) include hypoglycaemia, weight gain, infections, nausea and other gastrointestinal events [61]. Longterm safety data collection for newer agents is ongoing.

Sulfonylureas have a well-established safety profile because of their longevity (more than 60 years) in the market [62]. As a result of their mechanism of stimulating insulin secretion, they are associated with a higher risk of hypoglycaemia, weight gain and occasionally cardiovascular complications [63]. However, both efficacy (Fig. 2) and adverse-event profiles differ between the first- and second-generation sulfonylureas [7]. Generalizations for the efficacy and safety of sulfonylureas as a class should, therefore, be avoided [64]. Additionally, despite previous data, a recent prospective study showed no increased risk of severe hypoglycaemia with sulfonylureas [65].

Hypoglycaemia is an important consequence of treatment for diabetes, being associated with both clinical and economic costs. Clinical manifestations, such as falls, dysrhythmias, confusion and neuroglycopenia, are burdensome for the patient and may require medical intervention, resulting in increased resource utilization [66]. Severe hypoglycaemia is also a risk factor for cardiovascular disease in people with type 2 diabetes, as indicated in a systematic review and meta-analysis, supporting the idea that avoiding severe hypoglycaemia is important to prevent cardiovascular disease in this population [67].

In a retrospective study of a large US claims database, use of the DPP4i linagliptin was associated with lower incidence rates of hypoglycaemia compared with sulfonylureas available in the USA in patients initiating therapy as second line after metformin monotherapy [66]. However, information on the type of sulfonylurea used was not available; therefore, intraclass differences in the incidence of hypoglycaemia were not taken into account.

Differences have also been observed in hypoglycaemic risk between different sulfonylureas, which may be explained by variations in their molecular structure [32] and pharmacological profiles $[14,31]$. It is known that glibenclamide is long acting and forms active metabolites, which increase the risk for prolonged and severe hypoglycaemia. This risk is less with later sulfonylureas, which have inactive metabolites [68]. Gliclazide is the only one reported in the class that does not bind to Epac2 (exchange protein directly activated by cAMP 2 and also known as Rap guanine nucleotide exchange factor 4), a stimulating factor for insulin exocytosis, and has a reduced risk of hypoglycaemia [32]. Several meta-analyses have compared the risk of hypoglycaemia between different sulfonylureas, with numerous reports of a significantly lower risk of hypoglycaemia with the later-generation sulfonylureas compared with others in the class $[14,31,69,70]$. In a model-based meta-analysis conducted by Maloney et al., important differences were identified both between and within classes of anti-hyperglycaemic drugs used to treat type 2 diabetes. Despite increased rates of hypoglycaemia with sulfonylureas as a class, the risk was notably lower with gliclazide (Fig. 4) [37], which is also mirrored in the head-to-head GUIDE trial comparing gliclazide with glimepiride [71]. The ADVANCE trial compared intensive blood glucose control using daily gliclazide MR (target HbA1c value $6.5 \%$ or less) versus standard blood glucose control (with target HbA1c levels defined on the basis of local guidelines). In the intensive treatment group, $90.5 \%, 73.8 \%$ and $40.5 \%$ of participants were treated with gliclazide MR, metformin and insulin, 


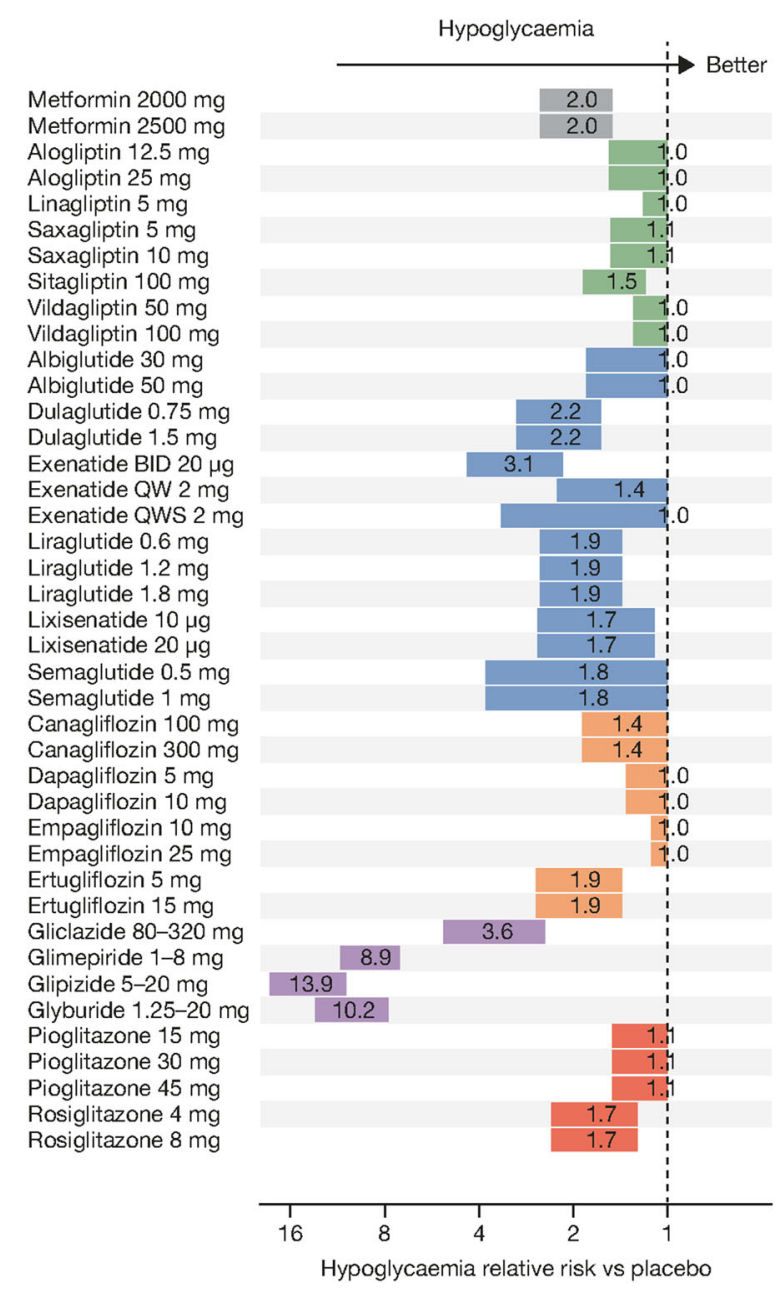

Fig. 4 Risk of hypoglycaemia by molecule and dosage (drug-naive population with a baseline HbA1c of $8.0 \%$ and a baseline weight of $90 \mathrm{~kg}$, after 26 weeks of treatment) [37]. Boxes represent standard deviation. BID twice a day, HbAlc glycated haemoglobin, QW once a week, QWS auto-injection. Reproduced with permission from Maloney et al. [37]

respectively. In the standard treatment group, $1.6 \%, 67.0 \%$ and $24.1 \%$ were treated with gliclazide MR, metformin and insulin, respectively. While severe hypoglycaemia was marginally higher in the intensive therapy group, it was still uncommon $(2.7 \%$ vs $1.5 \%$ in the standard-control group; $P<0.001)$ despite the intensive arm achieving an HbA1c of $6.5 \%$ [25]. Additionally, a recent analysis of ADVANCE confirmed that the risk of severe hypoglycaemia associated with the intensive regime did not vary across different levels of kidney function $(P=0.83)$. This analysis confirmed that the risk-benefit profile of an intensive glycaemic control strategy is consistent across those with both preserved and reduced kidney function [72]. With this in mind, patients with type 2 diabetes can benefit from intensive glucose lowering regardless of kidney function, as long as attention is given to the prevention of hypoglycaemia [72]. Moreover, by providing proper education regarding the signs and symptoms of hypoglycaemia and its prompt management, and subsequent reduction of dosage of the sulfonylurea doses, the problem can be managed, at least in part.

Clinical practice should be evidence-based, although this may not necessarily be the case. In a recent study of general practitioner prescribing practices in England, the authors were surprised to find the continued use of the older sulfonylureas tolbutamide and glibenclamide, despite the recommendation that these agents should not be generally prescribed for the treatment of type 2 diabetes [73]. These findings show that the intra-class variability of sulfonylureas may not have been communicated strongly enough.

Special circumstances, such as fasting during Ramadan (estimated to be observed by $80-90 \%$ of Muslims with diabetes), need to be considered when using glucose-lowering therapies, because of the increased risk of hypoglycaemia $[14,31]$. This risk varies depending on the agent, with no significant differences in the rate of any hypoglycaemic events observed for gliclazide and the DDP4i vildagliptin in a randomized trial [74]. The trial, which included frequent physician contact and Ramadan-focused advice as part of the intervention, provides reassurance on the use of vildagliptin and gliclazide plus metformin in these circumstances [74].

It has been reported that weight gain is an undesirable consequence of therapy with sulfonylureas [14]. However, variations have again been noted within this drug class. In the UKPDS trial, weight gain of approximately $4 \mathrm{~kg}$ was reported in the first 3 years after glibenclamide initiation [23]. In the ADVANCE study, weight gain in the intensive glucose control arm, using 
gliclazide-based treatment, was reported as less than $1 \mathrm{~kg}$ [25]. More recently, the CAROLINA data showed weight gain associated with sulfonylureas to be relatively low, even when compared to a 'weight neutral' agent such as the DPP4i linagliptin, with an average betweengroup difference in weight of $-1.5 \mathrm{~kg}(95 \% \mathrm{CI}$ $-1.8,-1.3)$ [55].

\section{AFFORDABILITY AND ACCESSIBILITY OF TYPE 2 DIABETES TREATMENT}

In both developing and developed countries, cost is an integral part of evaluation of a medication, and is often reflected in clinical guidelines or recommendations. For example, the National Institute for Health and Care Excellence in the UK provides "advice on effective, good value healthcare" [75]. For such a widespread condition as diabetes, defining optimal cost-effective approaches to care is essential [20]. In general, insulin, SGLT2i, DPP4i and GLP-1RA medications are more costly than the relatively inexpensive metformin and sulfonylureas [20]. Glimepiride and gliclazide daily treatment costs are 7 and 8 Indian rupees (Rp), respectively, compared with $44 \mathrm{Rp}$ for the DPP4i vildagliptin [76]. Also of note, in India, approximately $80 \%$ of people pay 'out of pocket' for their type 2 diabetes management, posing a significant economic burden.

In Thailand, the cost of treatment was reported to be approximately US\$465/year for DPP4i, US $\$ 15.05$ for metformin and US $\$ 4.52$ for sulfonylureas [77]. These examples from developing countries indicate that although healthcare systems may differ from country to country, large relative differences are observed between sulfonylureas and other agents in terms of treatment costs.

This price difference is also seen in developed countries. In the UK, metformin and sulfonylureas are generally available at low cost ( $£ 17-50$ and $£ 34-173$, respectively, for 1 year of treatment), while the other agents are markedly more expensive (£391-482, £414-434 and $£ 830-1432$ for thiazolidinediones, DPP4i and GLP-1RA, respectively) [78].
In 2017, an independent Canadian group updated a systematic review, network metaanalysis and cost-effectiveness analysis of second-line therapies for type 2 diabetes [79, 80]. The review considered the comparative efficacy and safety of using second-line drugs for adults with type 2 diabetes with inadequate glycaemic control on metformin monotherapy. The therapies considered included sulfonylureas, SGLT2i, DPP4i and GLP-1RA. The analysis concluded that the addition of a sulfonylurea remains the most cost-effective second-line therapy for patients. Threshold analyses indicated that the costs of the newer agents SGLT2i, DPP4 $i$ and GLP-1RA would have to be reduced by $60-70 \%$ in order to match the cost-effectiveness of sulfonylureas as second-line treatment [79]. A similar report was published by a WHO expert group, recommending only metformin, short-acting sulfonylureas and regular human insulin in all low- and middle-income countries, unless there is a compelling need to use the newer agents [81].

However, numerous cost-effectiveness analyses are emerging, suggesting that newer oral agents may be cost-effective compared with sulfonylurea. Such analyses have been considered in the WHO guidelines, which highlight that industry-funded cost-effectiveness analyses tend to report cost-effectiveness of newer treatments [82-86], while independent studies favour sulfonylureas $[26,62]$. A specific example of the disparity in these cost-effectiveness trials is shown by a systematic review of DPP4i versus sulfonylureas in which DPP4i appeared to be more cost-effective [87]. However, this was based on a limited number of industry-funded studies and did not take into account low-resource settings and associated access issues. Another trial in this type of setting in Thailand found that DPP4i did not, in fact, appear to be more cost-effective when compared with sulfonylureas [88].

The WHO has developed a clinical guideline on treatment intensification in low-resource settings, which applies to both low- and highincome countries [81]. The drug classes under consideration included sulfonylureas, SGLT2i, DPP4i, thiazolidinediones and insulin. The first recommendation is to "give a sulfonylurea to 
patients with type 2 diabetes who do not achieve glycaemic control with metformin alone or who have contraindications to metformin (strong recommendation, moderatequality evidence)". These agents produce similar and statistically significant improvements in HbA1c. Taking into account the higher cost of newer agents, the panel decided that recommending the new agents for universal use as second- or third-line treatment in resourcelimited settings would be premature.

The International Diabetes Federation Access to Medicines and Supplies for People with Diabetes report in 2017 analysed the main barriers to access of diabetes medicine from the perspective of patients and healthcare professionals. Despite some low-income regions, such as Brazil, having free distribution of metformin, sulfonylureas and insulin in all of their pharmacies, in this analysis, availability of the range of diabetes medicines was much lower in lowand middle-income countries compared with high-income countries (Table 2) [16]. Similarly, the PURE [Prospective Urban Rural Epidemiology] study examined the availability and affordability of metformin, sulfonylureas and insulin across multiple regions of the world [15]. Availability was defined as the presence of medication in the pharmacy on the day of audit and medicines were defined as affordable if the cost was less than $20 \%$ of the capacity to pay (household income minus food expenditure). The authors concluded that availability and affordability of essential diabetes medicines were poor in low- and middle-income countries. With these two reports combined, it is clear that access remains a major issue with diabetes management and treatment decisions should be made with this in mind.

In its 2018 guidelines on pharmacological agents for managing diabetes in low-resource settings, the WHO noted that sulfonylureas are currently more affordable than newer oral antihyperglycaemic agents for people who pay 'out of pocket' [1]. Consequently, they are likely to be more accessible. This supports the South Asia consensus on diabetes management, which highlighted that cost is an important consideration in this region of the world, as a majority of patients are not covered under medical insurance [32]. As a result, sulfonylureas could be the oral glucose-lowering agent of choice in these countries. Furthermore, oral administration and daily dosing should benefit adherence to medication. Single-pill combinations of two or more diabetic drugs are known to increase patient adherence compared with two-pill therapy [32]. A scored, breakable, extended release, oncedaily, single-pill combination of a second-generation sulfonylurea and metformin was found to be effective in controlling blood glucose in a large proportion of patients with type 2 diabetes

Table 2 Countries with availability of diabetes therapies, access survey by income group [16]

\begin{tabular}{|c|c|c|c|c|c|c|}
\hline & \multicolumn{3}{|c|}{ Always available to purchase } & \multicolumn{3}{|c|}{$\begin{array}{l}\text { Available to purchase at least three-quarters of the } \\
\text { time }\end{array}$} \\
\hline & $\begin{array}{l}\text { High-income } \\
\text { countries }\end{array}$ & $\begin{array}{l}\text { Middle-income } \\
\text { countries }\end{array}$ & $\begin{array}{l}\text { Low-income } \\
\text { countries }\end{array}$ & $\begin{array}{l}\text { High-income } \\
\text { countries }\end{array}$ & $\begin{array}{l}\text { Middle-income } \\
\text { countries }\end{array}$ & $\begin{array}{l}\text { Low-income } \\
\text { countries }\end{array}$ \\
\hline Metformin & $28 / 32(88)$ & $23 / 36(64)$ & $2 / 10(20)$ & $31 / 32(97)$ & $32 / 36(89)$ & $5 / 10(50)$ \\
\hline Sulfonylurea & $27 / 32(84)$ & $16 / 30(53)$ & $1 / 9(11)$ & $31 / 32(97)$ & $23 / 30(77)$ & $4 / 9(44)$ \\
\hline DPP4i & $24 / 28(86)$ & $7 / 26(27)$ & $2 / 8(25)$ & $26 / 28(93)$ & $16 / 26(62)$ & $4 / 8(50)$ \\
\hline GLP-1RA & $20 / 26(77)$ & $4 / 23(17)$ & $2 / 6(33)$ & $23 / 26(88)$ & $11 / 23(48)$ & $3 / 6(50)$ \\
\hline SGLT2i & $19 / 23(83)$ & $3 / 19(16)$ & $1 / 5(20)$ & $21 / 23(91)$ & $9 / 19$ (47) & $2 / 5(40)$ \\
\hline
\end{tabular}

Data presented are no. (\%) countries reporting $100 \%$ or $>75 \%$ availability

$D P P 4 i$ dipeptidyl peptidase 4 inhibitors, GLP-1RA glucagon-like peptide 1 receptor agonists, $S G L T 2 i$ sodium-glucose cotransporter 2 inhibitors 
in India, and risk of hypoglycaemia was low $[89,90]$. The findings of this trial are important to note, as they give rise to a potential synergy between the pharmacodynamic profiles of metformin and sulfonylureas. Specifically, the respective weight loss and gain may counteract each other, although this requires further investigation.

The relationship between medication cost and adherence is well established, and there is a wide variation in adherence to diabetic medication worldwide, with reported non-adherence rates of approximately $40 \%$ in India and 50\% in Malaysia [91]. This issue is also important in countries such as Nigeria and India, where the majority of patients pay 'out of pocket'. In a study of patients with type 2 diabetes attending a tertiary hospital clinic in Nigeria, oral antihyperglycaemic agents (metformin alone or in combination) were the most prescribed drugs. According to study participants, common factors that may affect adherence to medications included cost of treatment (20.2\%) and nonavailability of prescribed medications (10\%) [91]. Even in higher-income countries, patients may be deterred from initiating essential medications because of cost, undermining adherence and risk factor control, as reported in an observational, new-prescription cohort study that evaluated the effect of out-of-pocket cost on medication initiation and adherence in patients with diabetes in California, USA [92].

Essential medicines are defined by the WHO as "those that satisfy the priority healthcare needs of the population" and, as such, it lists five diabetes-related medicines on its Model List of Essential Medicines (short-acting insulin, intermediate insulin, metformin, glucagon and sulfonylurea, and gliclazide) [93].

\section{CONCLUSIONS}

In line with the few published recommendations focused on resource-restricted settings, such as the WHO recommendations, the ADA/ EASD consensus statement notes that "access, treatment cost, and insurance coverage should all be considered when selecting glucose-lowering medications" [20]. The release of this statement is essential in providing an evidence base for balanced and actionable guidance that should ultimately be considered for global guidelines, where context-specific recommendations are lacking. Newer agents certainly have a role to play in the management of type 2 diabetes and may be appropriate as add-on treatments in certain subpopulations, such as those at higher risk of cardiovascular events and where accessibility and cost allow. However, a pragmatic approach is required in regions where resources are limited.

In such restricted-resource settings, sulfonylureas are recommended as the treatment of choice for type 2 diabetes when metformin alone is inadequate to achieve glucose targets. Despite the apparent "low-cost but more side effects" slogan introduced across much of the literature, second-generation sulfonylureas have demonstrated efficient glycaemic control, benefits in microvascular and macrovascular outcomes, cardiovascular safety and less hypoglycaemia than older-generation agents. More importantly, these therapies represent an accessible and affordable treatment option for patients with restricted choices. Looking to the future, when costs may be reduced for newer agents, the benefits of sulfonylureas continue to be supported by a robust and long-standing evidence base.

\section{ACKNOWLEDGEMENTS}

The views expressed are those of the authors and not necessarily those of the NHS, the NIHR or the Department of Health.

Funding. This work and the Rapid Service Fee were funded by Servier.

Medical Writing Assistance. Medical writing assistance was provided by Rachel Byrne, $\mathrm{PhD}$ and Karen Brayshaw, PhD of Complete HealthVizion. This assistance was funded by Servier.

Authorship. All named authors meet the International Committee of Medical Journal 
Editors (ICMJE) criteria for authorship for this article, take responsibility for the integrity of the work as a whole, and have given their approval for this version to be published.

Authorship Contributions. All authors contributed equally and were responsible for the literature search, writing and review of the manuscript.

Disclosures. Viswanathan Mohan reports grants, fees and others from Servier, Abbott, Merck Sharp \& Dohme, Novartis, Novo Nordisk, Eli Lilly, Lifescan Johnson \& Johnson, Sanofi Aventis, Roche Diagnostics, AstraZeneca, M/s USV Limited and Dr. Reddy's Laboratories. Kamlesh Khunti reports grants, fees and others from AstraZeneca, Boehringer Ingelheim, Novartis, Novo Nordisk, Sanofi-Aventis, Lilly, Servier, Merck Sharp \& Dohme, Berlin-Chemie AG/Menarini Group, Roche, Napp, Janssen and Pfizer. Kamlesh Khunti also acknowledges support from the National Institute for Health Research Collaboration for Leadership in Applied Health Research and Care - East Midlands (NIHR CLAHRC - EM), the NIHR Leicester Biomedical Research Centre. Siew P. Chan reports grants, fees and others from AstraZeneca, Boehringer Ingelheim, Eli Lilly, Janssen, Merck Sharp \& Dohme, Merck, Novartis, Novo Nordisk, Sanofi-Aventis and Servier. Fadlo F. Filho reports grants, fees and others from Novo Nordisk, AstraZeneca, Abbott, Bayer, Lilly, Sanofi, Pfizer, Janssen Cilag and Takeda. Nam Q. Tran reports grants, fees and others from Servier, Sanofi, Novartis, Novo Nordisk, Eli Lilly, AstraZeneca and Merck Sharp \& Dohme. Kaushik Ramaiya reports grants, fees and others from World Diabetes Foundation, MRC, DANIDA and Novo Nordisk. Shashank Joshi reports grants, fees and others from Abbot, Sanofi, USV, Serdia, Eli Lilly, Novo Nordisk, Lupin, Boehringer Ingelheim, Glen Mark, Franco India, AstraZeneca, Roche Diabetes Care and Johnson \& Johnson. Ambrish Mithal reports grants, fees and others from Novo Nordisk, Eli Lilly, Sanofi, Merck Sharp \& Dohme, Johnson \& Johnson, Boehringer Ingelheim, AstraZeneca, Novartis, Eris Life Sciences, USV, Lupin Laboratories, Dr Reddy's Laboratories,
Biocon and Glenmark Pharmaceuticals. Maïmouna N. Mbaye reports grants, fees and others from Servier, Novartis, Novo Nordisk and Sanofi Aventis. Nemencio A. Nicodemus Jr. reports grants, fees and others from Servier, Merck Sharp \& Dohme, Novartis, Novo Nordisk, Eli Lilly, Johnson \& Johnson, Sanofi Aventis, AstraZeneca and LRI-Therapharma. Tint S. Latt reports grants, fees and others from Servier, Novartis, Zifam Pharmaceutical Co., Mega Life Science and the World Diabetes Foundation for the National Survey of Prevalence of Diabetes and Risk Factors for Non-communicable Diseases. Linong Ji reports grants, fees and others from Eli Lilly, Bristol-Myers Squibb, Novartis, Novo Nordisk, Merck, Bayer, Merck Sharp \& Dohme, Takeda, Sanofi, Roche, Boehinger Ingelheim and AstraZeneca. Ibrahim N. Elebrashy reports grants, fees and others from Servier, Abbott, Merck Sharp \& Dohme, Novartis, Novo Nordisk, Eli Lilly, Sanofi, Amgen, AstraZeneca, Boehringer Ingelheim and Merck Sorono. Jean C. Mbanya reports grants, fees and others from Sanofi, Servier, Novo Nordisk, Merck and AstraZeneca.

Compliance with Ethics Guidelines. This article is based on previously conducted studies and does not contain any studies with human participants or animals performed by any of the authors.

Open Access. This article is distributed under the terms of the Creative Commons Attribution-NonCommercial 4.0 International License (http://creativecommons.org/licenses/ by-nc/4.0/), which permits any noncommercial use, distribution, and reproduction in any medium, provided you give appropriate credit to the original author(s) and the source, provide a link to the Creative Commons license, and indicate if changes were made.

\section{REFERENCES}

1. World Health Organization. Guidelines on secondand third-line medicines and type of insulin for the control of blood glucose levels in non-pregnant adults with diabetes mellitus. https://apps.who.int/ 
iris/bitstream/handle/10665/272433/9789241550284eng.pdf?ua=1. Accessed May 14, 2019.

2. International Diabetes Federation. IDF Diabetes Atlas. Eighth edition. https://www.idf.org/ouractivities/advocacy-awareness/resources-and-tools/ 134:idf-diabetes-atlas-8th-edition.html. Accessed May 13, 2019.

3. Wild S, Roglic G, Green A, Sicree R, King H. Global prevalence of diabetes. Estimates for the year 2000 and projections for 2030. Diabetes Care. 2004;27: 1047-53.

4. Wu Y, Ding Y, Tanaka Y, Zhang W. Risk factors contributing to type 2 diabetes and recent advances in the treatment and prevention. Int J Med Sci. 2014;11:1185-200.

5. NCD Risk Factor Collaboration (NCD-RisC). Worldwide trends in diabetes since 1980: a pooled analysis of 751 population-based studies with 4.4 million participants. Lancet. 2016;387:1513-30.

6. Chambers JC, Zhang W, Zabaneh D, et al. Common genetic variation near melatonin receptor MTNR1B contributes to raised plasma glucose and increased risk of type 2 diabetes among Indian Asians and European Caucasians. Diabetes. 2009;58:2703-8.

7. Chatterjee S, Khunti K, Davies MJ. Type 2 diabetes. Lancet. 2017;389:2239-51.

8. Barma PD, Ranabir S, Prasad L, Singh TP. Clinical and biochemical profile of lean type 2 diabetes mellitus. Indian J Endocrinol Metab. 2011;15(suppl 1):S40-3.

9. Shrivastava U, Misra A. Need for ethnic-specific guidelines for prevention, diagnosis, and management of type 2 diabetes in South Asians. Diabetes Technol Ther. 2015;17:435-9.

10. Shrivastava U, Misra A, Gupta R, Viswanathan V. Socioeconomic factors relating to diabetes and its management in India. J Diabetes. 2016;8:12-23.

11. Unnikrishnan R, Anjana RM, Mohan V. Diabetes in South Asians: is the phenotype different? Diabetes. 2014;63:53-5.

12. Unnikrishnan R, Gupta PK, Mohan V. Diabetes in South Asians: phenotype, clinical presentation, and natural history. Curr Diab Rep. 2018;18:30.

13. The Lancet Diabetes \& Endocrinology. Forging paths to improve diabetes care in low-income settings. Lancet Diabetes Endocrinol. 2017;5:565.

14. Khunti K, Chatterjee S, Gerstein HC, Zoungas S, Davies MJ. Do sulphonylureas still have a place in clinical practice? Lancet Diabetes Endocrinol. 2018;6:821-32.

15. Chow CK, Ramasundarahettige $\mathrm{C}, \mathrm{Hu} \mathrm{W}$, et al. Availability and affordability of essential medicines for diabetes across high-income, middle-income, and low-income countries: a prospective epidemiological study. Lancet Diabetes Endocrinol. 2018;6: 798-808.

16. International Diabetes Federation. Access to medicines and supplies for people with diabetes. https://www.idf.org/our-activities/advocacy-awareness/ resources-and-tools/106:global-survey-on-access-tomedicines-and-supplies-for-people-with-diabetes.html. Accessed May 13, 2019.

17. American Diabetes Association. 1. Improving care and promoting health in populations: standards of Medical Care in Diabetes-2019. Diabetes Care. 2019;42(suppl 1):S7-12.

18. Gopalan A, Mishra P, Alexeeff SE, et al. Prevalence and predictors of delayed clinical diagnosis of type 2 diabetes: a longitudinal cohort study. Diabet Med. 2018;35:1655-62.

19. Owolabi MO, Yaria JO, Daivadanam M, et al. Gaps in guidelines for the management of diabetes in low- and middle-income versus high-income countries-a systematic review. Diabetes Care. 2018;41:1097-105.

20. Davies MJ, D'Alessio DA, Fradkin J, et al. Management of hyperglycemia in type 2 diabetes, 2018. A consensus report by the American Diabetes Association (ADA) and the European Association for the Study of Diabetes (EASD). Diabetes Care. 2018;2018(41):2669-701.

21. American Diabetes Association. 9. Pharmacologic approaches to glycemic treatment: Standards of Medical Care in Diabetes-2019. Diabetes Care. 2019;42(suppl 1):S90-102.

22. Libianto R, Ekinci EI. New agents for the treatment of type 2 diabetes. Crit Care Clin. 2019;35:315-28.

23. UK Prospective Diabetes Study (UKPDS) Group. Intensive blood-glucose control with sulphonylureas or insulin compared with conventional treatment and risk of complications in patients with type 2 diabetes (UKPDS 33). Lancet. 1998;352: 837-53.

24. Rawshani A, Rawshani A, Franzén S, et al. Risk factors, mortality, and cardiovascular outcomes in patients with type 2 diabetes. $\mathrm{N}$ Engl J Med. 2018;379:633-44.

25. The ADVANCE Collaborative Group. Intensive blood glucose control and vascular outcomes in 
patients with type 2 diabetes. $\mathrm{N}$ Engl J Med. 2008;358:2560-72.

26. World Health Organization. Global report on diabetes. https://apps.who.int/iris/bitstream/handle/ 10665/204871/9789241565257_eng.pdf;jsessionid= 3DBB3F288B27894B0D19866F4C10C8A2? sequence= 1. Accessed May 15, 2019.

27. Makkar BM, Gupta D, Gainda A. Chapter 87. Clinical trials to clinical practice: role of sulfonylureas in today's practice. In: Munja YP, editor. API textbook of medicine. New Delhi: Association of Physicians India; 2013. p. 393-398.

28. Desai U, Kirson NY, Kim J, et al. Time to treatment intensification after monotherapy failure and its association with subsequent glycemic control among 93,515 patients with type 2 diabetes. Diabetes Care. 2018;41:2096-104.

29. National Institute for Health and Care Excellence. Type 2 diabetes in adults: management. NICE guideline (NG28). https://www.nice.org.uk/ guidance/ng28/resources/type-2-diabetes-in-adultsmanagement-pdf-1837338615493. Accessed May $14,2019$.

30. International Diabetes Federation Guideline Development Group. Global guideline for type 2 diabetes. Diabetes Res Clin Pract. 2014;104:1-52.

31. Colagiuri S, Matthews D, Leiter LA, Chan SP, Sesti $\mathrm{G}$, Marre M. The place of gliclazide MR in the evolving type 2 diabetes landscape: a comparison with other sulfonylureas and newer oral antihyperglycemic agents. Diabetes Res Clin Pract. 2018;143:1-14.

32. Kalra S, Aamir AH, Raza A, et al. Place of sulfonylureas in the management of type 2 diabetes mellitus in South Asia: a consensus statement. Indian J Endocrinol Metab. 2015;19:577-96.

33. Kahn SE, Haffner SM, Heise MA, et al. Glycemic durability of rosiglitazone, metformin, or glyburide monotherapy. N Engl J Med. 2006;355:2427-43.

34. Hayward RA, Reaven PD, Wiitala WL, et al. Followup of glycemic control and cardiovascular outcomes in type 2 diabetes. N Engl J Med. 2015;372: 2197-206.

35. Esposito K, Chiodini P, Bellastella G, Maiorino MI, Giugliano D. Proportion of patients at HbA1c target $<7 \%$ with eight classes of antidiabetic drugs in type 2 diabetes: systematic review of 218 randomized controlled trials with 78945 patients. Diabetes Obes Metab. 2012;14:228-33.

36. Hirst JA, Farmer AJ, Dyar A, Lung TWC, Stevens RJ. Estimating the effect of sulfonylurea on $\mathrm{HbA}_{1 \mathrm{c}}$ in diabetes: a systematic review and meta-analysis. Diabetologia. 2013;56:973-84.

37. Maloney A, Rosenstock J, Fonseca V. A model-based meta-analysis of 24 antihyperglycemic drugs for type 2 diabetes: comparison of treatment effects at therapeutic doses. Clin Pharmacol Ther. 2019;105: 1213-23.

38. Simpson SH, Lee J, Choi S, Vandermeer B, Abdelmoneim AS, Featherstone TR. Mortality risk among sulfonylureas: a systematic review and network meta-analysis. Lancet Diabetes Endocrinol. 2015;3: 43-51.

39. Home PD, Pocock SJ, Beck-Nielsen $H$, et al. Rosiglitazone evaluated for cardiovascular outcomes in oral agent combination therapy for type 2 diabetes (RECORD): a multicentre, randomised, open-label trial. Lancet. 2009;373:P2125-35.

40. Vaccaro O, Masulli M, Nicolucci A, et al. Effects on the incidence of cardiovascular events of the addition of pioglitazone versus sulfonylureas in patients with type 2 diabetes inadequately controlled with metformin (TOSCA.IT): a randomised, multicentre trial. Lancet Diabetes Endocrinol. 2017;5:887-97.

41. Monami M, Liistro F, Scatena A, Nreu B, Mannucci E. Short and medium-term efficacy of sodium glucose co-transporter-2 (SGLT-2) inhibitors: a metaanalysis of randomized clinical trials. Diabetes Obes Metab. 2018;20:1213-22.

42. Chen K, Kang D, Yu M, et al. Direct head-to-head comparison of glycaemic durability of dipeptidyl peptidase-4 inhibitors and sulphonylureas in patients with type 2 diabetes mellitus: a metaanalysis of long-term randomized controlled trials. Diabetes Obes Metab. 2018;20:1029-33.

43. Mamza J, Mehta R, Donnelly R, Idris I. Important differences in the durability of glycaemic response among second-line treatment options when added to metformin in type 2 diabetes: a retrospective cohort study. Ann Med. 2016;48:224-34.

44. Esposito K, Chiodini P, Maiorino MI, Bellastella G, Capuano A, Giugliano D. Glycaemic durability with dipeptidyl peptidase- 4 inhibitors in type 2 diabetes: a systematic review and meta-analysis of long-term randomised controlled trials. BMJ Open. 2014;4: e005442.

45. Mohan V, Anjana RM, Ranjit U, et al. Clinical profile of elderly patients (over 90 years) with type 2 diabetes seen at a diabetes centre in South India. Diabetes Technol Ther. 2019. https://doi.org/10. 1089/dia.2019.0219.

46. Mohan V, Shanthi Rani CS, Amutha A, et al. Clinical profile of long-term survivors and nonsurvivors 
with type 2 diabetes. Diabetes Care. 2013;36: 2190-7.

47. Nathan DM, Buse JB, Kahn SE, et al. Rationale and design of the glycemia reduction approaches in diabetes: a comparative effectiveness study (GRADE). Diabetes Care. 2013;36:2254-61.

48. Palmer SC, Mavridis D, Nicolucci A, et al. Comparison of clinical outcomes and adverse events associated with glucose-lowering drugs in patients with type 2 diabetes: a meta-analysis. JAMA. 2016;316:313-24.

49. Qian D, Zhang T, Zheng P, et al. Comparison of oral antidiabetic drugs as add-on treatments in patients with type 2 diabetes uncontrolled on metformin: a network meta-analysis. Diabetes Ther. 2018;9: 1945-58.

50. Wiviott SD, Raz I, Bonaca MP, et al. Dapagliflozin and cardiovascular outcomes in type 2 diabetes. N Engl J Med. 2019;380:347-57.

51. Cavender MA, Norhammar A, Birkeland KI, et al. SGLT-2 inhibitors and cardiovascular risk. An analysis of CVD-REAL. J Am Coll Cardiol. 2018;71: 2497-506.

52. Zelniker TA, Wiviott SD, Raz I, et al. SGLT2 inhibitors for primary and secondary prevention of cardiovascular and renal outcomes in type 2 diabetes: a systematic review and meta-analysis of cardiovascular outcome trials. Lancet. 2019;393: 31-9.

53. Zinman B, Wanner C, Lachin JM, et al. Empagliflozin, cardiovascular outcomes, and mortality in type 2 diabetes. N Engl J Med. 2015;373:2117-28.

54. Hernandez AF, Green JB, Janmohamed S, et al. Albiglutide and cardiovascular outcomes in patients with type 2 diabetes and cardiovascular disease (Harmony Outcomes): a double-blind, randomised placebo-controlled trial. Lancet. 2018;392:1519-29.

55. Webb DR, Davies MJ, Jarvis J, Seidu S, Khunti K. The right place for sulphonylureas today. Part of review the series: Implications of recent CVOTs in type 2 diabetes mellitus. Diabetes Res Clin Pract. 2019. https://doi.org/10.1016/j.diabres.2019.107836.

56. American Diabetes Association. Linagliptin and glimepiride have comparable cardiovascular safety effects in type 2 diabetes at high cardiovascular risk. http://www.diabetes.org/newsroom/press-releases/ 2019/linagliptin-and-glimepiride.html. Accessed July 2, 2019.

57. Marso SP, Bain SC, Consoli A, et al. Semaglutide and cardiovascular outcomes in patients with type 2 diabetes. N Engl J Med. 2016;375:1834-44.
58. Perkovic V, Jardine MJ, Neal B, et al. Canagliflozin and renal outcomes in type 2 diabetes and nephropathy. N Engl J Med. 2019;380:2295-306.

59. Perlman A, Heyman SN, Stokar J, Darmon D, Muszkat M, Szalat A. Clinical spectrum and mechanism of acute kidney injury in patients with diabetes mellitus on SGLT-2 inhibitors. Isr Med Assoc J. 2018;20:513-6.

60. Perkovic V, Heerspink HL, Chalmers J, et al. Intensive glucose control improves kidney outcomes in patients with type 2 diabetes. Kidney Int. 2013;83: $517-23$

61. Karagiannis T, Paschos P, Paletas K, Matthews DR, Tsapas A. Dipeptidyl peptidase-4 inhibitors for treatment of type 2 diabetes mellitus in the clinical setting: systematic review and meta-analysis. BMJ. 2012;344:e1369.

62. Klarenbach S, Cameron C, Singh S, Ur E. Cost-effectiveness of second-line antihyperglycemic therapy in patients with type 2 diabetes mellitus inadequately controlled on metformin. CMAJ. 2011;183:E1213-20.

63. Kalra S, Khandelwal D. Modern sulfonylureas strike back-exploring the freedom of flexibility. Eur Endocrinol. 2018;14:20-2.

64. Schrijnders D, Kleefstra N, Landman GWD. Withinclass differences of the sulfonylureas should be accounted for. Diabetologia. 2015;58:1374-5.

65. Dunkley AJ, Fitzpatrick C, Gray LJ, et al. Incidence and severity of hypoglycaemia in type 2 diabetes by treatment regimen: a UK multisite 12-month prospective observational study. Diabetes Obes Metab. 2019;21:1585-95.

66. Raju A, Shetty S, Cai B, D’Souza AO. Hypoglycemia incidence rates and associated health care costs in patients with type 2 diabetes mellitus treated with second-line linagliptin or sulfonylurea after metformin monotherapy. J Manag Care Spec Pharm. 2016;22:483-92.

67. Goto A, Arah OA, Goto M, Terauchi Y, Noda M. Severe hypoglycaemia and cardiovascular disease: systematic review and meta-analysis with bias analysis. BMJ. 2013;347:f4533.

68. Douros A, Yin H, Yu OHY, Filion KB, Azoulay L, Suissa S. Pharmacologic differences of sulfonylureas and the risk of adverse cardiovascular and hypoglycemic events. Diabetes Care. 2017;40:1506-13.

69. Schopman JE, Simon AC, Hoefnagel SJ, Hoekstra JB, Scholten RJ, Holleman F. The incidence of mild and severe hypoglycaemia in patients with type 2 diabetes mellitus treated with sulfonylureas: a 
systematic review and meta-analysis. Diabetes Metab Res Rev. 2014;30:11-22.

70. Andersen SE, Christensen M. Hypoglycaemia when adding sulphonylurea to metformin: a systematic review and network meta-analysis. Br J Clin Pharmacol. 2016;82:1291-302.

71. Schernthaner G, Grimaldi A, Di Mario U, et al. GUIDE study: double-blind comparison of oncedaily gliclazide MR and glimepiride in type 2 diabetic patients. Eur J Clin Invest. 2004;34:535-42.

72. Ohkuma T, Zoungas S, Jun M, et al. Intensive glucose lowering and the risk of vascular events and premature death in patients with decreased kidney function: the ADVANCE trial. Diabetes Obes Metab. 2019. https://doi.org/10.1111/dom.13878.

73. Heald AH, Livingston $\mathrm{M}$, Bien Z, Moreno GYC, Laing I, Stedman M. The pattern of prescribing of glucose modulating agents for type 2 diabetes in general practices in England 2016/17. Int J Clin Pract. 2018;72:e13080.

74. Hassanein M, Abdallah K, Schweizer A. A doubleblind, randomized trial, including frequent patientphysician contacts and Ramadan-focused advice, assessing vildagliptin and gliclazide in patients with type 2 diabetes fasting during Ramadan: the STEADFAST study. Vasc Health Risk Manag. 2014;10:319-26.

75. National Institute for Health and Care Excellence. What we do. https://www.nice.org.uk/about/whatwe-do. Accessed May 14, 2019.

76. Limaye D, Todi K, Shroff J, et al. Cost-effectiveness study of antidiabetic drugs in type 2 diabetes mellitus patients from Mumbai, India. Int J Community Med Public Health. 2017;4:3180-5.

77. Permsuwan U, Dilokthornsakul P, Saokaew S, Thavorn K, Chaiyakunapruk N. Cost-effectiveness of dipeptidyl peptidase-4 inhibitor monotherapy in elderly type 2 diabetes patients in Thailand. Clinicoecon Outcomes Res. 2016;8:521-9.

78. Campbell IW. Comparing the actions of older and newer therapies on body weight: to what extent should these effects guide the selection of antidiabetic therapy? Int J Clin Pract. 2010;64:791-801.

79. CADTH. New drugs for type 2 diabetes: second-line therapy-science report. CADTH Therapeutic Review Vol. 4, No. 1b. https://www.cadth.ca/sites/ default/files/pdf/TR0012_T2D_Science_Report.pdf. Accessed May 15, 2019.

80. Genere N, Montori VM. Review: Newer second-line drugs for diabetes are not more cost-effective than sulfonylureas. Ann Intern Med. 2018;168:JC8.
81. Roglic G, Norris SL. Medicines for treatment intensification in type 2 diabetes and type of insulin in type 1 and type 2 diabetes in low-resource settings: synopsis of the World Health Organization guidelines on second- and third-line medicines and type of insulin for the control of blood glucose levels in nonpregnant adults with diabetes mellitus. Ann Intern Med. 2018;169:394-7.

82. Erhardt W, Bergenheim K, Duprat-Lomon I, McEwan $P$. Cost effectiveness of saxagliptin and metformin versus sulfonylurea and metformin in the treatment of type 2 diabetes mellitus in Germany: a Cardiff diabetes model analysis. Clin Drug Investig. 2012;32:189-202.

83. Gordon J, McEwan P, Hurst M, Puelles J. The costeffectiveness of alogliptin versus sulfonylurea as add-on therapy to metformin in patients with uncontrolled type 2 diabetes mellitus. Diabetes Ther. 2016;7:825-45.

84. Granström O, Bergenheim K, McEwan P, Sennfält $\mathrm{K}$, Henriksson M. Cost-effectiveness of saxagliptin $\left(\right.$ Onglyza $\left.{ }^{\circledR}\right)$ in type 2 diabetes in Sweden. Prim Care Diabetes. 2012;6:127-36.

85. Sabale U, Ekman M, Granström O, Bergenheim K, McEwan P. Cost-effectiveness of dapagliflozin $\left(\right.$ Forxiga $^{\circledR}$ ) added to metformin compared with sulfonylurea added to metformin in type 2 diabetes in the Nordic countries. Prim Care Diabetes. 2015;9: $39-47$.

86. Charokopou M, McEwan P, Lister S, et al. The costeffectiveness of dapagliflozin versus sulfonylurea as an add-on to metformin in the treatment of type 2 diabetes mellitus. Diabet Med. 2015;32:890-8.

87. Baptista A, Teixeira I, Romano S, Carneiro AV, Perelman J. The place of DPP-4 inhibitors in the treatment algorithm of diabetes type 2 : a systematic review of cost-effectiveness studies. Eur J Health Econ. 2017; 18:937-65.

88. Permsuwan U, Dilokthornsakul P, Thavorn K, Saokaew S, Chaiyakunapruk N. Cost-effectiveness of dipeptidyl peptidase-4 inhibitor monotherapy versus sulfonylurea monotherapy for people with type 2 diabetes and chronic kidney disease in Thailand. J Med Econ. 2017;20:171-81.

89. Kalra S, Das AK. Epidemiologic surveillance of glycemic response to a scored, breakable, extended release, fixed dose combination of gliclazide and metformin in persons with type 2 diabetes. J Assoc Physicians India. 2017;65:38-41.

90. Mohan V, Chopra V, Sanyal D, Jain S, Jayaprakashsai J. Treatment of type 2 diabetes with a breakable extended release gliclazide formulation 
in primary care: the Xrise study. J Assoc Physicians India. 2015;63:26-9.

91. Fadare J, Olamoyegun M, Gbadegesin BA. Medication adherence and direct treatment cost among diabetes patients attending a tertiary healthcare facility in Ogbomosho, Nigeria. Malawi Med J. 2015;27:65-70.

92. Karter AJ, Parker MM, Solomon MD, et al. Effect of out-of-pocket cost on medication initiation, adherence, and persistence among patients with type 2 diabetes: the Diabetes Study of Northern California (DISTANCE). Health Serv Res. 2018;53: 1227-47.

93. World Health Organization. WHO model list of essential medicines. 20th list (March 2017). https:// www.who.int/medicines/publications/essentialmed icines/20th_EML2017.pdf. Accessed June 3, 2019. 